\title{
Entre a realidade jornalística e a realidade social: o jornalismo como forma de acesso ao cotidiano
}

\section{Frederico de Mello Brandão Tavares}

\section{Resumo}

Este ensaio pretende pensar a relação entre 0 jornalismo e o cotidiano, partindo de um ponto de vista teórico orientado pela noção de realidade. Tomase este conceito como eixo norteador, apontando-se para seus principais fundamentos no âmbito de perspectivas sociológicas e filosóficas, manifestadas aqui pelo olhar reflexivo do campo da chamada Teoria do Jornalismo. Nesse movimento, busca-se discutir a ideia de uma "realidade jornalística" e sua importância para o pensamento acerca dos produtos e práticas informativas, bem como da leitura que estes fazem da ambiência social. No percurso do texto, chama-se atenção para o papel da linguagem e para como lógicas da "realidade social" se entrecruzam às lógicas da "realidade jornalística", constituindo e fazendo parte, de maneira indissociável, de uma mediação da vida cotidiana.

\section{Palavras-Chave}

Realidade Social. Realidade Jornalística. Cotidiano. Linguagem. Mediação.

\section{Frederico de Mello Brandão Tavares |}

fredericombtavares@yahoo.com.br

Doutor em Ciências da Comunicação pela Universidade do Vale do Rio dos Sinos (UNISINOS). Jornalista e mestre pela Universidade Federal de Minas Gerais (UFMG). Professor do Programa de Pós-Graduação em Comunicação e Linguagens da Universidade Tuiuti do Paraná (UTP-PR).

\section{Introdução}

A noção de realidade, sem dúvida, encontra-se no centro das discussões que voltam seu olhar para o cotidiano. No eixo desse debate, confrontamse um viés mais ontológico - da realidade como contexto dado, existente em estado bruto, um a priori, anterior aos sentidos - e outro mais interpretativo, que toma o real como produto de uma construção social - envolto por construtos que perpassam, principalmente, a linguagem e as práticas de interação social. Essa segunda corrente, que combate a perspectiva essencialista (ou materialista) da primeira, não nega, em seus diversos pontos de vista teóricos, que a realidade deve ser tomada como uma "qualidade pertencente a fenômenos que reconhecemos terem um ser independente de nossa própria volição" (BERGER; LUCKMANN, 2000, p. 11). ${ }^{1}$ No entanto, fenomenologicamente, a vida cotidiana "apresenta-se como uma realidade interpretada pelos homens e subjetivamente dotada de sentido para eles na medida em que forma um mundo coerente" (BERGER; LUCKMANN, 2000, p. 35). 
Segundo Berger e Luckmann (2000, p. 39), "a realidade da vida cotidiana está organizada em torno do 'aqui' de meu corpo e do 'agora' do meu presente. Este 'aqui e agora' é o foco de minha atenção à realidade da vida cotidiana" e, por isso, ao se constituir na interação intersubjetiva entre os sujeitos, dá a esta uma dimensão espacial e temporal. "A realidade da vida diária, porém, não se esgota nessas presenças imediatas, mas abraça fenômenos que não estão presentes 'aqui e agora'. Isto quer dizer que experimento a vida cotidiana em diferentes graus de aproximação e distância, espacial e temporal"2 (BERGER; LUCKMANN, 2000, p. 39).

Na transcendência de tempo e espaço que sugerem os autores, a linguagem tem papel decisivo. Tanto na objetivação das experiências quanto na tipificação delas mesmas. E, justamente por possibilitar essa transcendência, a linguagem permite a construção de diferentes pontes entre zonas da realidade cotidiana, integrando-as em uma totalidade de sentido (BERGER; LUCKMANN, 2000, p. 61). Uma dinâmica que dota a linguagem de uma potencial característica, que é a de presentificação de uma série de "objetos" que estão ausentes do "aqui e agora" do contexto da interação e que podem ser atualizados, "trabalhando" em prol do acervo cotidiano do conhecimento, principalmente 0 senso comum.

Se resgatamos as contribuições sociológicas das teorias do cotidiano e seus diálogos com outros estudos, ${ }^{3}$ e pensamos o papel que 0 jornalismo possui hoje no contexto da midiatização (BERGER, 2008; FAUSTO NETO, 2008; GOMES, 2007), vislumbramos não só a trama de sentido que compõe 0 "mundo da vida" $\mathrm{e}$ que é resgatada pelos diversos produtos da prática informativa, mas também a produção do conhecimento na vida social. Na tensão entre saberes expertos e do senso comum, bem como na tensão entre uma prática jornalística e um público diversificado, muitas vezes leigo, o papel do jornalismo torna-se evidente, articulando tanto essa produção do conhecimento quanto suas coafetações intrínsecas e contextuais. Seja na marcação de uma dimensão espacial e temporal, seja na "convocação" de distintas experiências (jornalísticas e sociais).

Esse algo "intransponível" da realidade também é lembrado por Umberto Eco (2000), que diz que na realidade, há um "núcleo duro", que resiste à interpretação; aquilo que o autor nomeia de uma "persistência do real".

Por focalizarem os processos intersubjetivos em relação ao tempo e ao espaço, Berger e Luckmann (2000, p. 44) irão valorizar em sua reflexão a "estrutura temporal da vida cotidiana", já que "a temporalidade é uma propriedade intrínseca da consciência".

Esse resgate das teorias do cotidiano e sua associação ao jornalismo é realizada de maneira interessante e crítica, a partir de outro viés, por Moretzsohn (2007).

Como aponta Martín Algarra (1993), "el mundo de la vida no es sólo lo que nos rodea, sino que también incluye eso mismo en cuanto que percebido, en cuanto que objeto de la conciencia” (MARTín ALGARRA, 1993, p. 73). Ou seja, do ponto de vista fenomenológico, o mundo da vida é um mundo natural e social, "[...] es el escenario que pone límites a mi acción y a nuestra acción recíproca. Es el ámbito donde yo actúo, al que se dirigen mis acciones y sobre el que yo opero" (MARTín ALGARRA, 1993, p. 74). 
Dado esse contexto, esse ensaio toma o conceito de realidade como eixo norteador, debatendo e retomando seus principais fundamentos no âmbito de perspectivas sociológicas e filosóficas específicas, lendo-os a partir do campo do Jornalismo. Nesse movimento, buscamos apontar para a ideia de uma "realidade jornalística" e a contribuição de tal formulação para o pensamento acerca da relação entre 0 jornalismo e 0 cotidiano.

\section{Teorias do Jornalismo pelas teorias do cotidiano: encaminhamentos para uma certa realidade}

No âmbito do Jornalismo, a ideia de uma "construção da realidade" também perpassa a constituição de "sua" realidade, a "realidade jornalística". Historicamente, há uma passagem, nesse campo, ${ }^{5}$ entre um contexto de valorização de uma pretensa objetividade, que apontava o jornalismo como atividade neutra de relatar a "realidade social", para um momento em que 0 reconhecimento da subjetividade passa a indicar a construção que o jornalismo exercia em seus relatos sobre 0 mundo (GIMÉNEZ ARMENTIA; BERGANZA CONDE, 2008; SÁDABA, 2001, 2007). Tal percurso está relacionado não só a uma mudança na produção de textos e nos preceitos profissionais que foram decisivos na construção de seu ethos, mas também à formulação de distintos pontos de vista teóricos que analisaram o jornalismo e a notícia como objeto de estudo em destaque.

Segundo Gaye Tuchman (2009), uma perspectiva sociológica mais tradicional sobre as notícias, que auxiliou durante muito tempo uma concepção da notícia como "espelho" da realidade, referia-se aos textos jornalísticos como reflexo da estrutura da sociedade. Nessa perspectiva, a estrutura social seria responsável pela produção de normas e atitudes definidoras da vida social, definindo o que é de interesse ou tem importância para os cidadãos.

É suposto que as notícias digam respeito a esses tópicos reconhecíveis. Socializados nessas atitudes sociais e nas normas profissionais, os jornais cobrem, seleccionam e difundem histórias sobre temas identificados como interessantes ou importantes. Em virtude do cumprimento desta função por parte dos jornalistas, as notícias reflectem a sociedade: as notícias apresentam à sociedade um espelho das suas preocupações e interesses (TUCHMAN, 2009, p. 93).

Em contraponto a essa perspectiva, uma posterior abordagem interpretativa das notícias ${ }^{6}$ (TUCHMAN, 2009) passa a enfatizar a atividade dos jornalistas

Como aponta Érik Neveu (2006, p. 63), a noção de campo aplicada ao jornalismo convida a "pensar o espaço do jornalismo como um universo estruturado por oposições ao mesmo tempo objetivas e subjetivas, a perceber cada publicação e cada jornalista dentro da rede de estratégias, de solidariedades e de lutas que o ligam a outros membros do campo".

Montero (1993, p. 35 apud SOUSA, 2002, p. 139) ao explicar sobre a aproximação entre as teorias sociológicas interpretativas e 0 jornalismo, afirma: "A perspectiva interpretativa reúne as aportações [..] da sociologia fenomenológica, da etnometodologia e do interacionismo simbólico. A sua descrição da comunicação [...] refletiu-se sobre todo o processo de mediação na criação de significados. Enfatizou principalmente o papel das organizações mediáticas e a sua influência na forma e no conteúdo da comunicação [..], os processos sociais de interpretação e de leitura e, em última instância, o papel ativo do público frente aos meios de comunicação". 
e das organizações jornalísticas, em vez das normas sociais. Nesse ponto de vista, as notícias não perdem sua ligação com as estruturas sociais, mas passam a ser vistas como produto de uma construção profissional e institucional. As notícias, nesse sentido, não espelham a realidade. "Ajudam a constituí-la como um fenômeno social partilhado".?

As notícias registram a realidade social e são simultaneamente um produto dessa mesma realidade, na medida em que fornecem aos seus consumidores uma abstraç̧ão selectiva intencionalmente coerente, mesmo podendo descurar certos pormenores. [...] A abstracção e a representação selectivas da informação, e a atribuição reflexiva de significado aos acontecimentos enquanto notícias são características naturais da vida cotidiana (TUCHMAN, 2009, p. 98-99).

Para Tuchman (2009, p. 98), que, além das teorias fenomenológicas, traz conceitos de outras correntes sociológicas interpretativas para pensar o jornalismo, há nos textos sobre os acontecimentos um processo reflexivo, já que estes últimos estão inseridos na mesma "realidade que eles próprios caracterizam, registram ou estruturam". Além disso, ao utilizarem-se de relatos (termos, enunciações ou narrativas) para dizer do cotidiano, os jornalistas, como atores sociais, podem fazê-lo atribuindo sentidos aos acontecimentos independentemente "do contexto no qual esses relatos são produzidos ou processados". Uma ação indexical sobre a realidade que prevalece, muito, no caso da notícia - uma vez que essa pode, em vários momentos, abster-se de uma melhor contextualização dos fatos concretos para os quais se dirige - mas que, se vista em conjunto com a reflexividade que a acompanha, permite pensar, em termos etnometodológicos, na contextualização mais ampla de certos fenômenos e na maneira como ganham sentido no cotidiano.

A autora ainda relembra, nesse viés construcionista, a contribuição das teorias "goffmanianas" na formulação de uma perspectiva para a análise dos enquadramentos jornalísticos ${ }^{8}$ e 0 trabalho de Peter Berger e Thomas Luckmann, A construção social da realidade, para pensar a apreensão dos fatos do mundo. Uma apreensão que, mesmo se vista pelo jornalismo, está envolvida, em um processo de construção, pelo impacto das instituições e dos processos sociais na criação e definição dos fatos sociais. 0 que quer dizer, como coloca Tuchman, que mesmo considerando o contexto de partilhamento coletivo de significado para a compreensão da realidade, as notícias, uma vez ligadas a uma dimensão social e histórica, atuam não só definindo e redefinindo, "constituindo e reconstituindo as significações sociais; mas 
também definindo e redefinindo, constituindo e reconstituindo modos de fazer as coisas - os processos existentes nas instituições existentes" (TUCHMAN, 2009, p. 104). ${ }^{9}$

Traquina (2001) situa dois grupos de teorias que "partilham o paradigma da notícia como construção social": a teoria estruturalista e a teoria etnoconstrucionista. Como explica 0 autor, para ambas as teorias, "as notícias são 0 resultado de processos complexos de interação social entre os agentes sociais: os jornalistas e as fontes de informação; os jornalistas e a sociedade; os membros da comunidade profissional, dentro e fora da sua organização" (TRAQUINA, 2001, p. 85-86, grifo do autor). Neste paradigma construtivista, as notícias são vistas como uma espécie de índice do "real", mas possuem formas textuais para enquadrarem, principalmente, os acontecimentos. Há nesse contexto, portanto, uma valorização do papel da linguagem, o que evidencia a quebra com um viés especular sobre a produção noticiosa e coloca em evidência seu processo subjetivo. A escolha da narrativa é "orientada pela aparência que a 'realidade' assume para o jornalista, pelas convenções que moldam a sua percepção e fornecem o repertório formal para a apresentação dos acontecimentos, pelas instituições e rotinas" (TRAQUINA, 2001, p. 87). Apesar de partilharem uma orientação "construtivista", ${ }^{10}$ algumas diferenças entre as duas correntes podem ser citadas.

A visão estruturalista - de viés macrossociológico - dá maior importância ao papel das fontes oficiais (o que, em alguma medida, a aproxima de uma perspectiva mais determinista), bem como "defende a posição de que os valoresnotícia dos membros da comunidade jornalística têm um papel ideológico central na reprodução da 'ideologia dominante'” (TRAQUINA, 2001, p. 115). Já a visão etnoconstrucionista - viés microssociológico -, privilegia um maior grau de autonomia dos jornalistas, estando mais preocupada com as práticas profissionais e seu imbricamento junto às rotinas criadas para

Eduardo Medistch (2010, p. 19), com quem concordamos, sintetiza de forma precisa essa discussão, elaborando-a criticamente: "A perspectiva construcionista nos estudos da notícia [...] permitiu superar o empirismo ingênuo de feição positivista que, desde 0 século XIX, deu o tom das teorias normativas da profissão. No entanto, a dicotomia entre a perspectiva que via o jornalismo, singelamente, como um espelho da realidade, e aquela outra que demonstra o processo de construção que 0 caracteriza, tem sido empobrecedora em mais de um aspecto. 0 primeiro e mais óbvio é a simplificação da relação dialética entre subjetividade e objetividade (complexificada ainda mais pela intersubjetividade) na produção de conhecimento sobre a realidade. 0 segundo é 0 de transferir para a questão da construção da realidade, como através de uma correia de transmissão, por uma generalização demesdida, o desvendamento feito do processo de construção da notícia. No primeiro caso, o objetivismo ingênuo se contrapõe a um subjetivismo ingênuo; no segundo, a metáfora da total exterioridade se contrapõe à da total interiorização midiacêntrica, levando ao absurdo lógico de uma visão da construção da realidade esgotada pelo protagonismo da mídia".

10 Vale resgatar aqui a boa definição de Wilson Gomes (1993, p. 71) sobre o termo "construtivista" em sua discussão sobre a "importância dos conceitos de fato e verdade das teorias relativistas da notícia”: “'Construtivista’ é aquela posição acerca do conhecimento humano que se opõe à idéia de que o conhecimento tem a tarefa de espelhar e reproduzir a essência das coisas, que existiriam como tal fora da experiência e indiferentes a esta, afirmando, por sua vez, que o dado da experiência é organizado e constituído na própria experiência, de forma tal que no conhecimento jamais nos pomos em relação com as coisas mesmas e sim com as coisas tais quais se manifestam a nós, portanto, configuradas por formas e categorias cuja sede é o sujeito que conhece". 
o desenvolvimento do processo de produção das notícias. ${ }^{11}$

Em reflexão mais recente, Traquina (2004, p. 168) afirma que esse "filão de investigação que concebe as notícias como construção" rejeita a noção de "notícias como espelho do real" por diversas razões. Primeiramente, porque estabelece uma distinção "radical entre a realidade e os media noticiosos que devem 'refletir' essa realidade porque as notícias ajudam a construir a própria realidade". Em segundo lugar, porque, uma vez que o jornalismo trabalha com a linguagem, não existe nesta a possibilidade de uma transmissão direta "dos significados inerentes aos acontecimentos". E, em terceiro lugar, porque, segundo o viés construcionista, os meios de comunicação noticiosos estruturam sua representação dos acontecimentos devido a diversos fatores (profissionais, organizacionais, orçamentários etc.). ${ }^{12}$

Do ponto de vista jornalístico, todo esse processo, que relativiza e contextualiza teoricamente algumas correntes interpretativas, deixa claro como, no âmbito de uma atuação jornalística na "construção social da realidade", também desponta, pelas práticas de produção (ação e leitura) sobre os fenômenos do mundo, uma "realidade jornalística" específica. E esta pode ser tensionada pelos conceitos que oferecem as teorias acima citadas para pensar práticas sociais outras, e que, por esse motivo, é colocada em evidência tanto por sua dimensão pessoal quanto por sua dimensão institucional.

Nesse sentido, se pensamos os objetos jornalísticos no cruzamento entre uma realidade (social) e outra (jornalística), considerando aí tanto a reflexividade desse process $0^{13}$ quanto alguns eixos que o permeiam (instituição, experiência, conhecimento, interação, enquadramento etc.), cabe a pergunta: como o jornalismo vê a realidade? $0 u, o$ que é a realidade para o jornalismo? Qual a realidade do jornalismo? Se dizíamos acima da passagem de um viés objetivo para um outro mais subjetivo no pensamento da relação do jornalismo com 0 mundo (seja em termos profissionais, seja em

11 Pontes e Silva (2009, p. 45), em breve crítica sobre as teorias construcionistas no jornalismo, advertem: "muitas das abordagens construcionistas restringem suas análises à emissão da notícia, destacando as relações profissionais e políticas e deixando de lado o papel do público e da sociedade na constituição do jornalismo".

12 Neste texto, Traquina nomeia as duas teorias de viés construcionista como "estruturalista" (mesmo nome apontado em 2001) e "interacionista" (antes denominada como etnoconstrucionista). Apesar desta distinção, o ponto de vista sobre a relação jornalismo e realidade permanece: "Para a teoria interacionista, o mundo social e político não é uma realidade predeterminada e 'dura' que os jornalistas 'refletem': a atividade jornalística é, para estes teóricos, bem mais complexa do que a ideologia jornalística sugere" (TRAQUINA, 2001, p. 204).

13 Pontes e Silva (2009, p. 45), baseados nas concepções de Peter Berger e Thomas Luckmann e de John Searle sobre a construção social da realidade, afirmam o jornalismo dentro dessa lógica reflexiva. Como assinalam os autores, o jornalismo é "uma instituição plena, historicamente fundada e que, por isso, não apenas seria instituinte da realidade social, mas, igualmente, também instituído por ela". 
termos teóricos), tais questões ganham destaque e direcionam a proposta aqui encadeada.

\section{A realidade jornalística: aproximações pela linguagem}

Para Pontes e Silva (2009, p. 48), a partir das ideias de Berger e Luckmann para pensar a construção social da realidade e, nesse sentido, a "realidade jornalística", dois eixos devem ser pensados. Primeiramente, se partimos do pressuposto de que os fatos da sociedade se apresentam aos homens como coisas, "0 jornalismo possuiria uma realidade independente de qualquer ator individual, ainda que esse fosse o maior dono de conglomerados de mídia do mundo". Em segundo lugar, e por outro lado, se a sociedade é vista como "constituída pela atividade que expressa um significado subjetivo, ou seja, a realidade social é vivida pelo indivíduo que age nela", torna-se necessário reconhecer o que é o jornalismo para que este exista num universo de leitores e que "algumas dessas pessoas se especializem e tomem essa prática profissional como parte de sua subjetividade. Portanto, há um processo de ação no jornalismo e interiorização dessa ação na consciência dos indivíduos"
Esses dois eixos, contrapostos entre si - 0

primeiro propondo a realidade independente dos indivíduos, e o segundo propondo a realidade dependente dos indivíduos - são reunidos por Berger e Luckmann - como apontam Pontes e Silva (2009) - pelo conceito de dialética a partir da concepção marxista desse termo. Desse modo, "[...] tanto a realidade objetiva (externa ao indivíduo) quanto a subjetiva (interna ao indivíduo) compõem o que é a sociedade, tendo por força motriz desta a relação dialética entre cada realidade" (PONTES; SILVA, 2009, p. 49). Ou, nos dizeres de Berger e Luckmann (2000, p. 243): "[...] essa integração exige a sistemática consideração da relação dialética entre as realidades estruturais e 0 empreendimento humano de construir a realidade na história”. ${ }^{14}$

Se concordamos com Medina (2008) que o Jornalismo atua duplamente em relação ao contexto social no qual se encontra, reconhecendo-o e tecendo-o concomitantemente, essa ideia dialética, pode-se dizer, também aparece presente. Medina (2008), entretanto, enfatiza tal relação constituinte de um ponto de vista dialógico, que coloca em tensionamento 0 "real" e as "palavras sobre 0 real". (PONTES; SILVA, 2009, p. 49).

14 Ao retomar as reflexões do paradigma construcionista e relacioná-las a uma perspectiva que compreende 0 jornalismo como uma forma singular de produção do conhecimento, Sérgio Gadini afirma: "[...] todo produto jornalístico (seja ele voltado ao campo cultural, econômico ou político) 'trafica' e publiciza imagens da realidade social, à medida que o mesmo é identificado, consumido e apropriado pelo público. Ao estabelecer uma (inter) conexão com o mundo, o produto jornalístico presentifica a simultaneidade de uma enorme variedade de fenômenos, desenhando um mapa do universo social onde são recortados os acontecimentos noticiados pela mídia. Esse ato de produção social imaginária (e, pois, histórica) capacita o indivíduo a projetar novas relações e compreensões, possibilitando - pelo olhar singular do acontecimento pautado e discursivamente estruturado - outras noções da realidade, materializadas em uma forma de produção singular do conhecimento humano” (GADINI, 2007, p. 87). 
Do ponto de vista de Contrera (2004), em

contraponto a um olhar positivista sobre os

fenômenos do "mundo da vida", no caso jornalístico

("os fatos transformados em acontecimentos"), devese entender o real como sempre mediado. Como uma construção simbólica de um grupo social e que se faz compreendido a partir de consensos e convenções sociais; o que permite a existência de "diferentes reais" para diferentes grupos sociais. Ou seja, de um "reconhecimento empírico" sobre a realidade, deve-se pensar a imersão imediata desta em um processo de mediação, baseado no caráter duplo do ser humano, que inscreve 0 "real", sempre, numa dupla realidade: da percepção e da representaçãa. ${ }^{15}$

Contrera (2004) retoma criticamente o pensamento de algumas ciências "realistas-objetivistas" e diz que por mais que pensemos ou teorizemos sobre o "universo real concreto", estaremos sempre nos valendo de certas "estruturas cognitivas" para tais operações. Assim, dado esse caráter "relacional fundante" que permeia a realidade, devemos reconhecer que as "estruturas cognitivas certamente partem da experiência humana do real concreto, mas, com base em uma complexa rede de relações, criam um real outro, 0 real pensado, 0 real representado pelo universo do pensamento e da linguagem"

(CONTRERA, 2004, p. 17).

Medina (2008) e Contrera (2004) realizam abordagens diferentes no que diz respeito ao papel social da mídia e do jornalismo. Medina (2008), com quem mais nos identificamos, ainda reconhece - de maneira otimista, podemos dizer - a potência dos sujeitos (principalmente o jornalista) no desenvolvimento de um processo relacional que coloca em evidência questões relevantes para a sociedade, principalmente no que diz respeito a um retorno aos afetos como mediadores da compreensão do mundo e de um fazer profissional. Já Contrera (2004) apoia-se, a nosso ver, em uma lógica mais pessimista, que relata um abandono do "fazer midiático" em relação a questões importantes do cotidiano, uma espécie de "desinteresse pelas questões relativas ao real", o que seria resultado de um processo que nasce no próprio senso comum de nossa época. Tal visão, na verdade, denota uma postura em relação ao sujeito que, em algum momento, valoriza um viés de esgotamento, hoje, pela mídia, "da possibilidade de uma experiência cotidiana mais elaborada" (CONTRERA, 2004).

Para a autora, "a teoria semiótica dá o golpe final no que diz respeito a essa questão, demonstrando com toda clareza que não há um real objetivo quando se fala de percepção, de linguagem e de comunicação" (CONTRERA, 2004, p. 16).

16 Na visão "otimista" de Medina (2008), o uso da linguagem é assim reivindicado: "Jornalistas que narram tanto o cotidiano quanto 0 evento extraordinário são convidados a fertilizar o texto verbal com notações não verbais".

Em Contrera (2004), outra abordagem se faz presente: "Mas hoje a linguagem é confrontada pela fantasia hegemônica de uma comunicação global e perpétua - a Nova Ordem, o novo ciberespaço da linguagem - onde a ultrassimplificação das linguagens digitais prevalece sobre a complexidade figural nas linguagens naturais (CONTRERA, 2004, p. 29). Mesmo reconhecendo algumas "exceções", para a autora, vivemos hoje uma "crise contemporânea das competências simbólicas", que aponta negativamente para uma "morte" dos discursos sobre o real, um declínio da capacidade de criação simbólica do homem e sua resposta ao mundo; ambas submetidas a um universo midiático subjugado ao espetáculo ou à denúncia, que realiza pontes "sobre e para o nada". 
Entre uma visão e outra que trata do real e coloca em questão aspectos importantes para pensarmos o jornalismo, desponta uma perspectiva distinta sobre a presença e o uso da linguagem no cotidiano, ${ }^{16}$ mas que, mais que isso - e segundo nosso foco - reforça o papel desta na constituição de um pensamento sobre a "realidade social" e a "realidade jornalística". ${ }^{17}$

Assim, no que diz respeito a uma "realidade jornalística”, mais especificamente, é 0 reconhecimento da linguagem que aproxima as autoras. Pois, além de concordarem com 0 caráter relacional e mediado da realidade social - realidade esta que serve de referente ao "fazer jornalístico" -, deixam claro o duplo caráter daquilo que se pode chamar por "realidade jornalística": tanto 0 seu caráter de uma realidade construída e que se encontra em tensão com a realidade social (dela, também fazendo parte, dotando-a de sentido) quanto o seu caráter de contexto produtivo - locus de uma série de normas e preceitos formais e profissionais - onde a linguagem terá papel decisivo em sua configuração, independentemente do uso que se faça desta ou de como se reflita sobre ela (de maneira "positiva" ou "negativa").
Pela tensão existente entre a noção de linguagem e realidade, é fácil retomarmos a discussão entre objetividade e subjetividade no jornalismo. De acordo com Berger (2003, p. 33), o jornalista, "[...] quando mediador/cultural, não reivindica a objetividade, pois, por reconhecer-se sujeito da história, sabe que ao olhar o mundo faz deste um lugar social e que ao descrevê-lo o produz na mesma dimensão de uma ação social - de referendamento ou transformação". A reflexão da autora se baseia em um percurso que pormenoriza o jornalismo como relato sobre a realidade em relação a - principalmente - duas outras formas legitimadas de uso textual, a História e a Literatura. ${ }^{18}$

Nesse contexto, a priori, caberia ao jornalista a descrição, ao historiador a reconstrução do fato e ao ficcionista uma espécie de "repercussão subjetiva" sobre o que acontece no mundo. No entanto, como explica Berger (2003), se "a linguagem constitui e não descreve aquilo que é por ela representado", o jornalismo, menos que descrever, permitindo um acesso "instantâneo" ao "real", deve ser tomado, desde a notícia, pela ótica da construção de um acontecimento pela

17 Apesar de realizarmos essa distinção reconhecendo como ambas se interpenetram, vale retomarmos aqui uma interessante observação de Gouldner (1978) utilizada por Gonzalo Abril (1996) em sua reflexão sobre a relação cotidiano, notícia e ficção. Para Abril (1996, p. 1), o viés marxista de Gouldner (1978, p. 143-144) fala de uma interessante dialética entre as notícias e a vida cotidiana. Segundo ele, "para empezar, la noticia se presenta a sí misma como lo no rutinario, es decir, como algo separado y destacado de los ritmos fundamentales de la vida familiar, el trabajo, etc. De ahí que la noticia necesariamente censura y oculta aspectos de la vida, generando una especie de realidad social subprivilegiada, constituida precisamente por todo lo que el discurso noticioso presupone indigno de atención" (ABRIL, 1996, p. 1, grifos do autor).

18 "Nesta pequena associação, reconhecemos o jornalismo entre duas instâncias de saber: a ciência e a ficção. E podemos perguntar sobre sua relação com o saber do senso comum, com quem dialoga privilegiadamente pois 0 jornal fala do trivial, do banal, do cotidiano" (BERGER, 2003, p. 19). 
linguagem. A notícia, nesse viés, encontra-se inserida no interior de uma complexa rede produtiva, que não está dissociada, do ponto de vista discursivo, do imbricamento entre a produção da linguagem e a produção social geral. 0 jornalista, nesse sentido, é visto como sujeito e produz um discurso onde outros sujeitos estão enredados. E tal discurso encontra-se situado em algum lugar social, onde os vínculos da linguagem com o "real" e as maneiras como se dá essa vinculação devem ser observados (BERGER, 2003).

Berger e Tavares (2008) retomam a discussão da presença da linguagem no jornalismo e relembram que "[...] quando a linguagem passa a ser um problema do jornalismo, este perde o ponto de vista estruturante de sua concepção", sua objetividade em relação ao real. Nesse texto, os autores trabalham o tensionamento entre a noção de "giro linguístico" para o jornalismo - defendida por Chillón (1998) - e a noção de gêneros jornalísticos, colocando em questão tanto o formalismo presente nas definições de tipos de texto para o jornalismo quanto a necessidade desse para uma leitura especializada sobre o "real". Segundo Chillón ${ }^{19}$ (1998, p. 73, grifo do autor, tradução nossa):
Não existe uma só realidade objetiva externa aos indivíduos, mas múltiplas realidades subjetivas, inumeráveis experiências. E estas realidades subjetivas múltiplas e inevitáveis adquirem sentido para cada um e são comunicáveis para os demais na medida em que são verbalizadas: "integradas" em palavras e "vertebradas" em enunciados linguisticos. Os limites do mundo de cada um são definidos primordialmente pelos limites da linguagem que, em que, cada qual apreende, vive o mundo, seu mundo. ${ }^{20}$

Apesar de não realizarmos uma visada alicerçada em um viés discursivo e tampouco em um viés linguístico, ao pensarmos, em nossa argumentação, a "realidade jornalística" - que diz duplamente de sua ligação com fenômenos sociais e de uma dimensão ética e estética - sob um viés do relato, privilegiamos dois aspectos correlacionados: a constituição do jornalismo como "grande" narrativa contemporânea, "pulverizada" nos mais diversos meios de comunicação; e a existência, nesses meios, de diversas narrativas jornalísticas. Ou seja, no conjunto formado entre perspectivas sociológicas e linguísticas, ${ }^{21}$ que nos põem em contato com uma dimensão específica de produção de sentido a partir do jornalismo, estamos atentos para 0 relato (BORRAT, 2000) como resultado da produção

Rodrigo Alsina também retoma os dizeres de Chillón (1998) e associa essa formação semiótica de realidades múltiplas à ideia de cultura que, segundo ele, é formada pela "[...] paulatina decantación de esos enunciados linguísticos e icónicos, que en la medida em que son colectivamente asumidos, van formando un humus, un sedimento común para uso consciente e inconsciente de todos" (RODRIGO ALSINA, 2005, p. 46, grifo do autor).

20 Do original: "No existe una sola realidad objetiva externa a los individuos, sino multiples realidades subjetivas, inumerables experiencias. Y estas realidades subjetivas múltiples e inevitables adquiren sentido para cada uno y son comunicables para los demás en la medida en que son verbalizadas: engastadas en palabras y vertebradas en enunciados lingüísticos. Los límites del mundo de cada cual son definidos primordialmente por los límites del lenguaje con el que, en el que cada cual aprehende, vive el mundo, su mundo" (CHILLÓN, 1998, p. 73, grifos do autor).

21 Rodrigo Alsina (2005) tenta reunir essas duas perspectivas assumindo para seu trabalho de reflexão sobre a "construção da notícia" um viés sociossemiótico intercultural. 
jornalística e, mais que isso, para, em suas

objetivações de temas e acontecimentos, os traços e vestígios reveladores tanto dessa produção quanto das maneiras que a levam a construir significados sobre a, também fragmentada, "realidade social" e põem em evidência a relação indissociável desta com uma outra realidade, a jornalística.

\section{Duas realidades e uma só: práticas, construção e acesso ao cotidiano}

Cruzando as ideias de uma "realidade social" e de uma "realidade jornalística" (ambas construídas), evidencia-se, nessa ação, um tensionamento entre 0 uso específico da linguagem e uma série de competências profissionais que se realizam no interior de aparatos produtivos especializados (RODRIGO ALSINA, 2005), os mass media. Os jornalistas, diz Rodrigo Alsina (2005), atuam sob um processo institucionalizado de práticas socialmente legitimadas e, ao elaborarem, por meio da notícia (principalmente), uma espécie de "cotidiano que nos interessa", dizem, ao mesmo tempo, que cotidiano é esse.

Na reunião das "duas realidades", a "social" e a "jornalística", há, pois, uma ação comum, presente em ambas e que, na tensão entre uma e outra, se reveste de outras especificidades. Se na perspectiva sociológica temos a valorização das interações sociais como processo principal na troca de significados sobre o mundo e na construção da realidade, no caso jornalístico (ou da mídia em geral), ganha ênfase, no centro desse processo, um produto repleto de mensagens e conteúdos, que aciona, por tais especificidades, outras práticas interacionais. 0 que direciona nosso olhar e permite a síntese: no cruzamento entre a mediação presente nas relações sociais (realizada principalmente pela linguagem) e a mediação jornalística (também permeada pela linguagem e outros elementos éticos e estéticos), configura-se uma outra mediação, que soma elementos das distintas realidades aí reunidas e cria, de maneira reflexiva, formas de acesso ao cotidiano. ${ }^{22}$ Nos diversos produtos jornalísticos, uma mediação própria se faz presente tanto pelo uso diferenciado de técnicas produtivas próprias quanto pelo circuito comunicativo que emerge da ação jornalística ali presente e materializada. Uma vez que a participação do jornalismo na construção social da realidade pode ser vista sob a ótica mais ampla dos mecanismos que regem a elaboração da vida cotidiana na interação entre os sujeitos (as instituições e representações), há também, na "realidade jornalística", um contexto complexo de produção, circulação e reconhecimento que, em diferentes tempos e espaços, atinge 
ou possui níveis específicos de configuração, criando diversos processos interativos.

Nessa lógica, acontecimentos e temas, tomados como referentes jornalísticos, aparecem em produtos diversificados e são 0 resultado noticioso de um processo de produção de informação, que, na construção de significados sobre a vida social, está acionado por uma série de elementos que conduzem e constituem um processo mais amplo que diz respeito à vida cotidiana e seus "episódios" comunicativos.

0 "fazer jornalístico", nesse sentido, envolto pela leitura e proposição de uma "realidade" sobre a sociedade, compartilha de conceitos que permeiam 0 estoque cotidiano de conhecimentos, trazendo-os à tona e, portanto, reconhecendo-os de acordo com sua própria lógica (editorial e institucional). Além disso, no uso e convocação de um certo tipo de produção, que solicita e permite um jogo de recursos simbólicos específicos (tanto verbais quanto visuais), este fazer coloca em evidência um "aqui e agora", atualizado não apenas pelo presente ele que incorpora, mas por situações e códigos culturais de variadas temporalidades e distintos espaços, que dão a ver as diversas camadas da chamada "atualidade jornalística" e sua densa relação com a contemporaneidade.

De um ponto de vista comunicacional, se observamos a confluência de dinâmicas que dizem tanto das representações presentes nos "objetos jornalísticos" quanto das afetações que tais objetos possuem da vida social, sendo por ela, também, afetados e constituídos, forma-se um quadro no qual a construção de um saber jornalístico, um conhecimento acerca do "mundo da vida", encontra-se cercado por lógicas que dão a ver certas formas de vida e dizem sobre certos conteúdos, processos e experiências.

Nesse contexto, está configurada uma racionalidade jornalística, que respeita certos parâmetros, certos controles discursivos, mas que, ao mesmo tempo, orienta-se de uma especificidade que foge a esse regime. Tal racionalidade contém informações que buscam refletir uma racionalidade outra - contemporânea e social - encadeando uma série de saberes (discursos, conhecimentos) produzidos no interior de outras instituições sociais, em sistemas peritos (GIDDENS, 2002) específicos que habitam o cotidiano formal e informalmente. Tais saberes, reunidos dentro de um sistema perito determinado - 0 jornalismo (MIGUEL, 1999) - configuram, pois, uma "hermenêutica jornalística", cujas objetivações dão a ver distintas realidades. E 0 cruzamento de seus respectivos universos intersubjetivos (sociais) colocam em evidência a complexidade que mobiliza uma ação e, consequentemente, a constituição, pelo e no cotidiano, de uma realidade também - jornalística. 


\section{Referências}

ABRIL, Gonzalo. La noticia, lo cotidiano y el espejo de la ficción. CIC: Cuadernos de información y comunicación, Madrid, n. 2, p. 57-62, 1996.

BERGER, Christa; TAVARES, Frederico de Mello B. (Re)pensando o jornalismo: contribuições espanholas. Lumina, Juiz de Fora, v. 2, n. 2, p. 1-20, 2008.

BERGER, Christa. De São Paulo a Madrid. Das mediações à midiatização. Mediaciones Sociales. Revista de Ciencias Sociales y de la Comunicación, Madrid, v. 2, 2008.

Campos em confronto: a terra e 0 texto. 2. ed. Porto Alegre: Ed. UFRGS, 2003.

BERGER, Peter; LUCKMANN, Thomas. A construção social da realidade. Petrópolis, RJ: Vozes, 2000.

BORRAT, Héctor. El primado del relato. Anàlisi.

Quaderns de Comunicació i Cultura, Barcelona, n. 25, p. $41-60,2000$.

CHILLÓN, Albert. El "giro lingüístico" y su incidencia en el estudio de la comunicación periodística. Anàlisi. Quaderns de Comunicació i Cultura, Barcelona, n. 22, p. 63-98, 1998.

CONTRERA, Malena. Jornalismo e Realidade: a crise da representação do real e da construção simbólica da realidade. São Paulo: Mackenzie, 2004.

ECO, Umberto. Cinco escritos morales. Barcelona: Delbolsillo, 2000.

FAUSTO NETO, Antonio. Fragmentos de uma "analítica" da midiatização. Revista Matrizes, São Paulo, v. 1, p. 89-105, 2008.

GADINI, Sérgio Luiz. Em busca de uma teoria construcionista do jornalismo contemporâneo. Revista FAMECOS, Porto Alegre, v. 33, p. 79-88, 2007.

GIDDENS, Anthony. Modernidade e identidade. Rio de Janeiro: Jorge Zahar Editor, 2002.
GIMÉNEZ ARMENTIA, Pilar; BERGANZA

CONDE, Maria Rosa.

Género y Medios de Comunicación: un análisis desde la objetividad y la teoría del Framing. Madrid: Fragua, 2008.

GOMES, Pedro Gilberto. 0 processo de midiatização da sociedade. Paper PPGCC. São Leopoldo, 2007. 7 f. Não publicado.

GOMES, Wilson. Verdade e perspectiva. A questão da verdade e 0 fato jornalístico. Textos de Cultura e Comunicação, Salvador, v. 29, p. 63-83, 1993.

GOULDNER, Alvin. La dialéctica de la ideología y de la tecnología. Madrid: Alianza, 1978. Apud ABRIL, 1996.

MARTÍN ALGARRA, Manuel. La comunicación en la vida cotidiana. La fenomenología de Alfred Schütz. Pamplona: Ediciones Universidad de Navarra, 1993.

MEDINA, Cremilda. Ciência e jornalismo: da herança positivista ao diálogo dos afetos. São Paulo: Summus, 2008.

MEDITSCH, Eduardo. Jornalismo e construção social do acontecimento. In: BENETTI, Marcia; FONSECA, Virgínia Pradelina da Silveira.

Jornalismo e acontecimento: mapeamentos críticos. Florianópolis: Insular, 2010. p. 19-42.

MIGUEL, Luis Felipe. 0 jornalismo como sistema perito. Tempo Social - Revista de Sociologia da USP, São Paulo, v. 11, n. 1, p. 197-208, maio 1999. MONTER0, Maria Dolores. La información periodística y su influencia social. Barcelona: Labor/ Universitat Autònoma de Barcelona, 1993. Apud SOUSA, 2002.

MORETZSOHN, Sylvia. Pensando contra os fatos. Jornalismo e cotidiano: do senso comum ao sendo crítico. Rio de Janeiro: Revan, 2007.

NEVEU, Érik. Sociologia do jornalismo. São Paulo: Edições Loyola, 2006. 
PONTES, Felipe Simão; SILVA, Gislene. Jornalismo e realidade: da necessidade social de notícia. Revista Galáxia, São Paulo, n. 18, p. 44-55, dez. 2009.

RODRIGO ALSINA, Miquel. La construcción de la noticia. Ed. Rev. Ampl. Paidós: Barcelona, 2005.

SÁDABA, Teresa. Framing: el encuadre de las noticias. El binomio terrorismo medios. Buenos Aires: La Crujía, 2007.

. Origen, aplicación y límites de la "teoría del encuadre" (framing) en comunicación. Comuncicación y Sociedad, v. IX, 2001, p. 143-175.

SOUSA, Jorge Pedro. Teorias da notícia e do jornalismo. Chapecó: Argos, 2002.

TRAQUINA, Nelson. Teorias do jornalismo: porque as notícias são como são. Vol. 1. Florianópolis: Editora Insular, 2004.

0 estudo do jornalismo no século XX. São Leopoldo: Editora da Universidade do Vale do Rio dos Sinos, 2001.

TUCHMAN, Gaye. As notícias como uma realidade construída. In: ESTEVES, João Pisarra. Comunicação e sociedade. Lisboa: Livros Horizonte, 2009. p. 93-106. 


\section{Between journalistic reality and social reality: journalism as a means of access to daylife}

\section{Abstract}

This essay aims to consider the relation between journalism and daylife from a theoretical point of view guided by the notion of reality. We take this concept as a guideline, pointing to its main bases in the context of sociological and philosophical perspectives manifested by a reflective look of the field of so-called Theory of Journalism. In this movement, we seek to discuss the idea of a "journalistic reality" and its importance for thinking about products and information practices, as well as their reading of the social environment. In the course of the text, it called attention to the role of language and how the "social reality" logic intertwines the logic of "journalistic reality", forming part of a mediation of daylife in an inseparable way.

\section{Keywords}

Social Reality. Journalistic Reality. Daylife. Language. Mediation.

\section{Entre la realidade periodística y la realidad social: periodismo como una forma de acceso a la vida cotidiana}

\section{Resumen}

Este ensayo tiene como objetivo examinar teoricamente la relación entre el periodismo y la vida cotidiana desde la noción de la realidad. Se tiene este concepto como una guía, señalando sus bases principales en el contexto de las perspectivas sociológicas y filosóficas, manifestada aquí por la mirada reflexiva del campo de la llamada Teoría del Periodismo. En este movimiento, se busca discutir la idea de una "realidad periodística" y su importancia para pensar acerca de los productos y prácticas informativas, así como la lectura que estes desarrollan sobre su entorno social. En el transcurso del texto, se pone la atención sobre el papel del lenguaje y sobre las lógicas de la "realidad social", observando cómo estas lógicas se entrelazan a las lógicas de la "realidad periodística", influyendo (y constituyendo) en la mediación de la vida cotidiana.

\section{Palabras clave}

Realidad Social. Realidad Periodística. Cotidiano. Lenguaje. Mediación. 


\section{Expediente}

A revista E-Compós é a publicação científica em formato eletrônico da Associação Nacional dos Programas de Pós-Graduação em Comunicação (Compós). Lançada em 2004, tem como principal finalidade difundir a produção acadêmica de pesquisadores da área de Comunicação, inseridos em instituições do Brasil e do exterior.
E-COMPÓS I www.e-compos.org.br I E-ISSN 1808-2599

Revista da Associação Nacional dos Programas

de Pós-Graduação em Comunicação.

Brasília, v.15, n.1, jan./abr. 2012.

A identificação das edições, a partir de 2008

passa a ser volume anual com três números.

\section{CONSELHO EDITORIAL}

Afonso Albuquerque, Universidade Federal Fluminense, Brasil Alberto Carlos Augusto Klein, Universidade Estadual de Londrina, Brasil Álvaro Larangeira, Universidade Tuiuti do Paraná, Brasil Ana Carolina Damboriarena Escosteguy, Pontifícia Universidade Católica do Rio Grande do Sul, Brasil

Ana Gruszynski, Universidade Federal do Rio Grande do Sul, Brasil Ana Silvia Lopes Davi Médola, Universidade Estadual Paulista, Brasil André Luiz Martins Lemos, Universidade Federal da Bahia, Brasil Ângela Freire Prysthon, Universidade Federal de Pernambuco, Brasil Angela Cristina Salgueiro Marques, Faculdade Cásper Líbero (São Paulo), Brasil Antônio Fausto Neto, Universidade do Vale do Rio dos Sinos, Brasil Antonio Carlos Hohlfeldt, Pontifícia Universidade Católica do Rio Grande do Sul, Brasil Antonio Roberto Chiachiri Filho, Faculdade Cásper Líbero, Brasil Arthur Autran Franco de Sá Neto, Universidade Federal de São Carlos, Brasil Benjamim Picado, Universidade Federal Fluminense, Brasil César Geraldo Guimarães, Universidade Federal de Minas Gerais, Brasil Cristiane Freitas Gutfreind, Pontifícia Universidade Católica do Rio Grande do Sul, Brasil Denilson Lopes, Universidade Federal do Rio de Janeiro, Brasil Eduardo Peñuela Cañizal, Universidade Paulista, Brasil Eduardo Vicente, Universidade de São Paulo, Brasil Eneus Trindade, Universidade de São Paulo, Brasil Erick Felinto de Oliveira, Universidade do Estado do Rio de Janeiro, Brasil Florence Dravet, Universidade Católica de Brasilia, Brasil Gelson Santana, Universidade Anhembi/Morumbi, Brasil Gislene da Silva, Universidade Federal de Santa Catarina, Brasil Guillermo Orozco Gómez, Universidad de Guadalajara Gustavo Daudt Fischer, Universidade do Vale do Rio dos Sinos, Brasil Hector Ospina, Universidad de Manizales, Colômbia Herom Vargas, Universidade Municipal de São Caetano do Sul, Brasil leda Tucherman, Universidade Federal do Rio de Janeiro, Brasil Inês Vitorino, Universidade Federal do Ceará, Brasil Jnice Caiafa, Universidade Federal do Rio de Janeiro, Brasil Jay David Bolter, Georgia Institute of Technology Jeder Silveira Janotti Junior, Universidade Federal de Pernambuco, Brasil João Freire Filho, Universidade Federal do Rio de Janeiro, Brasil John DH Downing, University of Texas at Austin, Estados Unidos José Afonso da Silva Junior, Universidade Federal de Pernambuco, Brasil
José Carlos Rodrigues, Pontifícia Universidade Católica do Rio de Janeiro, Brasil José Luiz Aidar Prado, Pontifícia Universidade Católica de São Paulo, Brasil José Luiz Warren Jardim Gomes Braga, Universidade do Vale do Rio dos Sinos, Brasil Juremir Machado da Silva, Pontifícia Universidade Católica do Rio Grande do Sul, Brasil Laan Mendes Barros, Universidade Metodista de São Paulo, Brasil Lance Strate, Fordham University, USA, Estados Unidos Lorraine Leu, University of Bristol, Grã-Bretanha Lucia Leão, Pontifícia Universidade Católica de São Paulo, Brasil Malena Segura Contrera, Universidade Paulista, Brasil Márcio de Vasconcellos Serelle, Pontifícia Universidade Católica de Minas Gerais, Brasil Maria Aparecida Baccega, Universidade de São Paulo e Escola Superior de Propaganda e Marketing, Brasil Maria das Graças Pinto Coelho, Universidade Federal do Rio Grande do Norte, Brasil Maria Immacolata Vassallo de Lopes, Universidade de São Paulo, Brasil Maria Luiza Martins de Mendonça, Universidade Federal de Goiás, Brasil Mauro de Souza Ventura, Universidade Estadual Paulista, Brasil Mauro Pereira Porto, Tulane University, Estados Unidos Mirna Feitoza Pereira, Universidade Federal do Amazonas, Brasil Nilda Aparecida Jacks, Universidade Federal do Rio Grande do Sul, Brasil Paulo Roberto Gibaldi Vaz, Universidade Federal do Rio de Janeiro, Brasil Potiguara Mendes Silveira Jr, Universidade Federal de Juiz de Fora, Brasil Renato Cordeiro Gomes, Pontifícia Universidade Católica do Rio de Janeiro, Brasil Robert K Logan, University of Toronto, Canadá

Ronaldo George Helal, Universidade do Estado do Rio de Janeiro, Brasil Rose Melo Rocha, Escola Superior de Propaganda e Marketing, Brasil Rossana Reguillo, Instituto de Estudos Superiores do Ocidente, Mexico Rousiley Celi Moreira Maia, Universidade Federal de Minas Gerais, Brasil Sebastião Carlos de Morais Squirra, Universidade Metodista de São Paulo, Brasil Sebastião Guilherme Albano da Costa, Universidade Federal do Rio Grande do Norte, Brasil

Simone Maria Andrade Pereira de Sá, Universidade Federal Fluminense, Brasil Tiago Quiroga Fausto Neto, Universidade de Brasília, Brasil

Suzete Venturelli, Universidade de Brasilia, Brasil Valério Cruz Brittos, Universidade do Vale do Rio dos Sinos, Brasil Valerio Fuenzalida Fernández, Puc-Chile, Chile Veneza Mayora Ronsini, Universidade Federal de Santa Maria, Brasil Vera Regina Veiga França, Universidade Federal de Minas Gerais, Brasil

\section{COMISSÃO EDITORIAL}

Adriana Braga I Pontifícia Universidade Católica do Rio de Janeiro, Brasil

Felipe Costa Trotta I Universidade Federal Fluminense, Brasil

CONSULTORES AD HOC

Bruno Campanella, Universidade Federal Fluminense, Brasil

Gisela Grangeiro da Silva Castro, Escola Superior de Propaganda e Marketing, Brasi José Carlos Ribeiro, Universidade Federal da Bahia, Brasil

Luciana Panke, Universidade Federal do Paraná, Brasil

Micael Herschmann, Universidade Federal do Rio de Janeiro, Brasil

Tânia Márcia Cezar Hoff, Escola Superior de Propaganda e Marketing, Brasil

Virginia da Silveira Fonseca, Universidade Federal do Rio Grande do Sul, Brasil

EDIÇÃO DE TEXTO E RESUMOS I Susane Barros

SECRETÁRIA EXECUTIVA I Juliana Depiné

EDITORAÇÃO ELETRÔNICA I Roka Estúdio
COMPós I www.compos.org.br

Associação Nacional dos Programas de Pós-Graduação em Comunicação

Presidente

Julio Pinto

Pontifícia Universidade Católica de Minas Gerais, Brasil

juliopinto@pucminas.br

Vice-presidente

Itania Maria Mota Gomes

Universidade Federal da Bahia, Brasil

itania@ufba.br

Secretária-Geral

Inês Vitorino

Universidade Federal do Ceará, Brasil

inesvict@gmail.com 